\title{
Universidad Alas Peruanas 10 años de vida institucional
}

Jorge Lazo Arrasco*

* Destacado profesor universitario, ex-Rector de la Universidad Inca Garcilaso de la Vega; asesor de la Universidad Alas Peruanas. 
6 a Universidad es la vanguardia intelectual de la nación y, por lo mismo, un sentimiento vitai.La Universidad Alas Peruanas fue creada y empezó a funcionar a escasos cuatro años de la culminación del siglo XX. El siglo expiraba en plena evolución científico-tecnológica; la Física cuántica había contribuido a la fabricación de distintos aparatos tecnológicos y equipos sofisticados, como los celulares, las computadores, los videos, los cohetes, los mísiles, la Internet, etc.

La Universidad Alas Peruanas apareció cuando los medios de comunicación vinculaban aceleradamente al mundo y las computadores cambiaban el ritmo de la educación, del trabajo, de las relaciones empresariales y sociales. La globalización ya había escindido a la humanidad.

El siglo XX, bien denominado "el siglo de la angustia", por la serie de controversias que trajo consigo, estaba extinguiéndose. Con él quedaban atrás los recuerdos de las grandes y pequeñas guerras entre países; el azote del hambre, la pobreza y la miseria; el terror de las drogas y del sida; la despreciable violencia y el terrorismo atroz. El siglo XX había sido tan denso, que la periodificación por centurias, en adelante, sería irreal. Ni el hombre se escapó dei escenario. Se habı́ mucho de èl, de sus derechos, pero igual se lo pisoteó y vituperó.

Como si se tratara de una responsabilidad que debía asumir y de un cúmulo de problemas lacerantes que tenia que enfocar y resolver, como si fuera una entrega en vajilla de retos, la Universidad Alas Peruanas inició su propia función; comenzó con humildad pero, al mismo tiempo, con entereza, convicción, espíritu de lucha académica y profundo sentido humanista y peruanista.

El nacimiento de esta nueva casa de estudios universitarios provenía de una cooperativa del mismo nombre: Alas Peruanas, una cooperativa donde la fraternidad, la hermandad y la solidaridad caracterizan los principios de su desenvolvimiento; de una cooperativa en la que la ayuda resulta vital y las relaciones entre los socios esencialmente humana. De allí surgió la iniciativa de crear este centro universitario; de fomentar la educación como objetivo cooperativista; de contribuir al país en su progreso y desarrollo; y, más aun, de crear una universidad que no fuera elitista o selectiva, sino abierta a la colectividad; una 
universidad que constituyera una prueba elocuente de lo que es capaz una cooperativa y de lo elevado que pueden resultar sus proyecciones. Al fin y al cabo la cooperativa busca unidad en la vida, con base a la reciprocidad.

Diez años después es tiempo oportuno para evocar todo los realizado; para mirar y admirar su trayectoria; para echar una mirada retrospectiva; todo ello para que se permita colegir que cuanto se pensó y se hizo estuvo bien, que es factible la reingeniería y que todo lo que se haga posteriormente será mejor. La historia no enseña lo que debemos hacer, pero sí lo que podemos evitar; este es, precisamente, un buen mensaje de la pedagogía como historia y un camino para extraer epítetos que engloban la filosofía, la axiología y aun la metafísica. Alas Peruanas ya tiene historia propia, indiscutible filosofía y luz axiológica; por eso ha creado mística y ha motivado devoción y entrega. La universidad es historia porque crea historia.

La historia es la memoria de los tiempos, maestra de la vida y fuente de la verdad. La historia se escribe en función de los hombres. Son los hombres, indiscutiblemente, los que con su acción, han escrito la historia primigenia de la Universidad Alas Peruanas. Hombres que la soñaron, hombres que con inusitado tesón gestionaron y lograron la autorización y funcionamiento; pero hubo un hombre que se agigantó en la brega, que la construyó día a día, paso a paso; que venció escollos y superó obstáculos; que convirtió a la universidad en su propia pasión, en su pasión excluyente, hasta que logró su institucionalización. Ese hombre es el Dr. Fidel Ramírez Prado.
En esta reminiscencia se trata de exaltar los hechos sucedidos en los diez años de funcionamiento; es la vivencia de los testigos y protagonistas; la palabra fiel de quienes contribuyeron a la cristalización de los propósitos y el logro de las metas; la preocupación de los que asumieron cargos directivos y la colaboración de aquel grupo que trabajando en el anonimato, con gran emoción de Alas Peruanas, también escribieron la historia

La historia es una sucesión de generaciones. A la primera, en la Universidad Alas Peruanas, le correspondió la tarea más dura: creación y consolidación. Han pasado diez años.

Diez años en que hay mucho que enseñar y mucho que aprender. Diez años con mensajes que preservar, lemas que enarbolar y actitudes edificantes que exaltar. Diez años para comprobar que después del minuto más negro de la noche, aparece el minuto más luminoso de la aurora. Diez años para demostrar que todos los grandes procesos históricos emanan de una iniciativa, inquietud o acto de inspiración. Diez años para afirmar que los grandes hombres existen, con visión y coraje. Diez años para saber que la acción de los buenos sirve de remordimiento al oprobio de los malos. Diez años para explicar que es posible edificar obras magnificas cuya significación esté cifrada en su propia existencia. Diez años de vida universitaria suficientes para saber lo que es una universidad y lo que se puede y se debe hacer con ella. Diez años con gran profusión de actividades académicas con plenitud, madurez y experiencia. Diez años que ya obligan a rememorar el pasado para entrever el futuro... Diez años, en fin, totalmente UAP. 
Alas Peruanas, como Universidad, resultó pionera en muchas proyecciones. Delineó un perfil académico inédito; se ubicó al amparo de la ley en un diseño diferente al tradicional; se extendió física y académicamente hacia ciudades distinguidas del país. Llegó a cubrir una red formativa de Facultades, con sus respectivas carreras profesionales; combinó, en forma eficaz, la enseñanza con la investigación, desarrolladas en campos de experimentación propios: Huancavelica (Tullpacancha), Lambayeque (Mocupe), Lima (Pachacamac y Valle Chillón), Cajamarca (Bolívar), Piura (Castilla) son ; impulsó los medios de comunicación, con un canal de TV y emisoras radiales (Ventanilla y Arequipa); acogió a destacados pensadores, escuchando sus disertaciones y difundiendo sus producciones intelectuales; creó una editorial que le ha permitido participar en varias ferias internacionales y nacionales de libros y que ha editado más de cien títulos; se proyectó académicamente, fuera de las fronteras del país, para enlazarse con universidades foráneas, como las de La Habana (Cuba), Granada (España) y muchas otras más; firmó convenios múltiples con diversas empresas educativas, castrenses, comerciales e industriales; convocó a las comunidades para el análisis de sus problemas y orientación en la solución de los mismos.

Alas Peruanas fue pronto un motor incansable: conferencias, simposios, congresos, charlas vía correo electrónico, visitas destacadas, exhibiciones, promoción del arte y del deporte en todos los niveles y categorías, graduación y titulación de miembros de las Fuerzas Armadas y Policiales, etc. Innovó la educación a distancia, llegando a los lugares más recónditos del país, como las riberas del rió Amazonas.
Alas Peruanas fue un nombre que raudamente repercutió, en todas las esferas de la educación y la cultura. Produjo admiración, respeto e identificación en la sociedad. Espontáneamente tocaron sus puertas y acudieron al recinto del claustro gobernantes, intelectuales, artistas, empresarios, industriales, además de los miles de padres de familia, trayendo a sus hijos, para beber en la fuente de la sabiduría, alimentada por los docentes. Frecuentemente Alas Peruanas presentaba novedades, lo que le ha permitido su propia renovación.

La historia es devenir de hombres y hechos; cada generación le añade un eslabón; por eso es que el tiempo histórico, resulta irreversible, pero no discontinuo. La razón histórica es razón dialéctica, porque en la concepción de la dialéctica determinante, el futuro también está contenido en el presente; mirando atrás se avanza. En Alas Peruanas el tiempo jamás fue enajenante; siempre fue exultante y oportuno para continuar en el impulso. Alas Peruanas, a los 10 años, es universidad prístina, singular, distinta; es escuela de pensamiento, dispuesta al cambio, sacudida de todo matiz pringoso; nada la ha podido tornar obsoleta; ha sabido sortear tormentas, escollos y sobrevivir en forma admirable. Alas Peruanas es un remedo de ave fénix.

El arcaico adagio de que "el tiempo de oro" quedo atrás en Alas Peruanas. El Dr. Fidel Ramírez Prado cambió el concepto; ahora "El tiempo es hombre". Cuando el tiempo es hombre, las esperanzas emanan de la desesperación y el éxito estriba en la altura que se alcanza al rebotar. Cuando el tiempo es hombre su definición esté en el mismo, en la lucha que enfrenta y en los logros que alcanza. Cuando el tiempo es hombre, es creación de 
vida, un anhelo de vivir a plenitud incluso en los momentos angustiosos, cuando busca romper su vieja coyunda.

Este ensayo de reflexión sobre la Universidad Alas Peruanas, en su primera década es un intento que resume lo más significativo pero que apertura un nuevo reto para lo que venga después. Estas son ideas que fluyen para recalcar que en Alas Peruanas los hombres son de todas horas, sin descanso ni desmayo, sin remilgos ni candideces; hombres con mucha fe en sí mismos, en la cooperativa $y$ en el destino humano.

Finalmente, cabe agregar que en este comentario no se puede prescindir de mencionar lo más importante de la trayectoria: su génesis; la creación, autorización y funcionamiento; la exaltación de quienes la condujeron: los doctores Javier Pulgar Vidal y Fidel Ramírez Prado; la edad medieval de los procesos judiciales; el desarrollo de todos y cada una de las facultades; la contribución de cada organismo complementario estructural; la presencia docente; el flujo estudiantil; las actividades prevalentes en investigación, disertaciones, arte y deporte; el desarrollo físico e instrumental; la relación de convenios, de graduados y titulados; los libros y revistas publicados; las distinciones; el descifrado del logo; la influencia de la planificación, etc; en suma, todo lo que constituye función de una institución universitaria, pero la institución es mucho más que eso.

La Universidad Alas Peruanas es preocupación de todos los maestros, pero excepcionalmente de uno: Fidel Ramírez Prado.
En el núcleo de uno de los versos de su himno se resume con profunda nitidez la esencia de lo que es y debe ser el espíritu de la Universidad Alas Peruanas:

Alas de avance, alas de fe, alas de triunfo, sed de vencer.

Alas de avance: porque avanzar es enfrentar al futuro. El futuro no se espera, se construye diariamente. Resolver los problemas hoy es la mejor manera de diseñar el porvenir. Avanzar es descubrir, es innovar; es trascender sus propios límites.

Alas de fe: porque la fe no se analiza, se acepta creyendo para vivir emotivamente. La fe refuerza la razón; si la fe no se practica se pierde, se diluye. Sin la fe no se logra ni la resignación, ni el valor; menos la esperanza.

Alas de triunfo: porque triunfar no es lo más importante, es lo único. Triunfar es saber a dónde vamos, cómo vamos y para qué vamos. Triunfar es ambicionar positivamente. Hay que ser triunfadores.

Sed de vencer: porque vencer es derrotar a la adversidad; es tener valor para vivir y no para morir. Es sortear escollos y obviar obstáculos. Vencer es rebasar las selvas hamleteanas de la indecisión.

Porque se avanza con fe, con deseos de triunfar y de vencer. Este verso que, bien puede ser nuestro lema, cala hondo y estimula, emociona e impulsa a cristalizar todo propósito, conmueve lo más recóndito de nuestro ser y nos impulsa sin pausas a seguir adelante en el camino trazado hace diez años. 